\title{
Multiple species mating disruption of leafrollers in cherries in Central Otago
}

\author{
G.F. McLaren ${ }^{1}$, D.M. Suckling², A.M. El-Sayed ${ }^{2}$, B.T. Hislop ${ }^{3}$ and T.F.S. Jones ${ }^{3}$ \\ ${ }^{1}$ GF McLaren Research Limited, 53 Paterson Rd, RD2 Cromwell 9384, New Zealand \\ ${ }^{2}$ The New Zealand Institute for Plant E Food Research Limited, Private Bag 4704, \\ Christchurch, New Zealand \\ ${ }^{3} 45$ South Management Limited, State Highway 6, Cromwell 9342, New Zealand \\ Corresponding author: max.suckling@plantandfood.co.nz
}

\begin{abstract}
Mating disruption for leafrollers has been conducted on a commercial scale using a single multi-species pheromone dispenser on contiguous blocks of cherries in Central Otago for 4 years. Pheromone trap and packhouse results were collected from isolated untreated (65.4 ha) and pheromone-treated cherry orchard areas (76.4 ha) in the Cromwell district. In untreated cherry orchards, catches of light brown apple moth (Epiphyas postvittana) were exceptionally high (3.8 males/trap/day), with lower catches of Planotortrix octo (0.25 males/ trap/day). Catches of both species were strongly disrupted in the treated areas, reducing E. postvittana to 0.0036 moths/trap/day and P. octo to nil. Trap catches of both species have increased steadily over 5 years (2008/09 to 20012/13) in blocks not using mating disruption. Packhouse results showed that all of the fruit inspected from both treated and untreated areas were free of leafroller infestations in 2012/13. Insecticide use in the pheromone-treated areas was reduced by one application, compared with the areas without pheromone.
\end{abstract}

Keywords pheromone, mating disruption, cherry, Prunus avium, leafroller, Epiphyas postvittana, Planotortrix octo, Ctenopseustis obliquana.

\section{INTRODUCTION}

Cherries, Prunus avium, are now the most widely planted stonefruit crop in New Zealand, with 600 ha grown nationally (500 ha in Central Otago). In the past 10 years, cherries have displaced the more commonly reported stonefruit crops, apricots (Prunus armeniaca), peaches and nectarines (Prunus persica), in terms of both area planted and production, with approximately two-thirds of the cherry crop exported. Three leafrollers, light brown apple moth (Epiphyas postvittana) and the two endemic tortricids, green-headed leafroller (Planotortrix octo) and brown-headed leafroller (Ctenopseustis obliquana), along with the New Zealand flower thrips (Thrips obscuratus) are the main quarantine pests of this crop. Mating disruption of moths using synthetic sex pheromone is now a well-accepted tactic in many production systems (Witzgall et al. 2010; El-Sayed 2013), including several in New Zealand (Suckling et al. 2012a). It offers residue-free intervention, selective targeting of pest species, minimal interference with biological control agents and enhanced resistance management. 
Where certain leafroller species occur together in a region, as in Central Otago, they can be controlled using a single dispenser (Suckling et al. 2012a). McLaren et al. (1998) reported earlier success with leafroller control using two separate pheromone dispensers in comparatively large scale trials in Central Otago export stonefruit orchards (mainly apricots). One dispenser targeted E. postvittana (Suckling et al. 1990) and the other was a combined dispenser for P. octo and C. obliquana. A combined dispenser for all three species was methodically examined in area-wide trials on a mix of stonefruit crops in Central Otago in 2008 and 2009 (Suckling et al.2012a). However, the commercial development and use of the combined dispenser in Central Otago has since been focused largely on cherries.

The present project recorded the performance of the combined dispenser during 4 years when it was installed over approximately half of an extensive orchard area under the management of one company, 45 South Management Ltd, covering 142 ha planted in cherries in the Cromwell district. Many of these orchard "blocks" are privately owned, but are all run under one management, including the picking and packing of their export fruit. An indication of the presence of leafrollers in orchards was provided by trapping male moths in pheromone traps that attracted E. postvittana and $P$. octo in blocks both with and without dispensers. Insecticide records for each block were collected and compared between orchards with and without mating disruption treatments. The incidence of leafroller larvae in fruit was assessed by inspecting export cherries in the packhouse.

\section{MATERIALS AND METHODS \\ Leafroller species present}

Since cherries have, until recently, been a minor part of stonefruit exports from Central Otago, less information has been collected or published concerning the leafroller complex in cherry compared with other stonefruit crops. It was, therefore, necessary to establish that the leafroller species occurring in cherry fruits in Central Otago were similar. Ripe stonefruit, containing leafroller larvae, were collected from various Central Otago packhouses and orchards. Infested fruits were collected during harvest inspections of samples of generally 1500 fruit per cultivar from each orchard or block in each year from apricots, peaches or nectarines in orchards from Roxburgh, Alexandra and Cromwell during 2001-2008. While two such samples of cherries were inspected for pests in 2002 and 2003, the majority of the leafrollers from cherry fruits were supplied by packhouse staff in the Alexandra and Cromwell districts (this did not include 45 South). Larvae were removed from the fruit and reared to maturity on artificial diet (Singh 1983) so that the adults could be identified to species.

\section{Orchard blocks}

The majority (94\%) of the 151 ha orchard area was planted in cherry trees (various cultivars on 'Colt' rootstock) (142 ha), with the remaining areas being planted in apricots and plums. The cherry trees were generally planted at $5 \times 3.3 \mathrm{~m}$ spacings with 600 trees/ha (average block size $=$ 6.7 ha, range $=2-31$ ha). Roughly half of the area (76.4 ha) consisted of 25 contiguous blocks that were all relatively close to the 45 South packhouse (45.05 ${ }^{\circ}$ South; $169.17^{\circ}$ East). The remaining 65.6 ha consisted of isolated blocks, with five of the most distant being $17 \mathrm{~km}$ north, one being $9 \mathrm{~km}$ east and four $5 \mathrm{~km}$ south of the packhouse. The central area around the packhouse was protected with single three-species pheromone dispensers for mating disruption each year for 4 years, while the outlying blocks were not treated with pheromone dispensers.

\section{Pheromone traps and dispensers}

Pheromone traps were installed at the rate of one trap/2 ha, and aimed at gathering information on the activity of leafrollers in cherry orchards with or without dispensers. They were generally run over the known flight period for leafrollers in the region, starting in November, and ceasing at the end of cherry harvest in late January. In 2008/09, nine sets of pheromone traps for each of three leafroller species were operated in blocks without dispensers. In the following 4 years, leafroller activity was monitored by pheromone traps for E. postvittana and P. octo only, with 30-37 E. postvittana traps operated in blocks with dispensers, and 12-21 in blocks without them. 
Similarly, 7-12 $P$. octo traps were managed in dispenser blocks in 2011/12 and 2012/13 and 6-13 in non-dispenser blocks (see Table 2). Epiphyas postvittana and P. octo traps and lures were initially purchased from Plant \& Food Research, Auckland, then after 2011 from Etech Crop Solutions Ltd, Auckland. The traps were operated with weekly checks until the last cherries were harvested on 30/1/2013. In 2012/13 a total of 64 E. postvittana and $24 P$. octo traps were installed during 8-12 November 2012. The two component lures used in the traps were described by Suckling et al. (2012a). Large-scale mating disruption commenced at 45
South in 2009/2010 using dispensers containing a pheromone blend described elsewhere (Walker et al. 2011; Suckling et al. 2012b). Dispensers were installed each year between 10-15 November (600/ha). They were hand-applied from the ground, approximately $1.8-2 \mathrm{~m}$. above ground level within the tree canopy. Most blocks were completely enclosed with bird-proof netting. The netting on the sides remained in place year-round but the overhead nets were closed over from late November; nets probably help retain pheromone within the block by reducing wind speed.

Table 1 Numbers of each species of adult leafrollers reared from larvae extracted from naturally-infested stonefruit, collected from Central Otago orchards and packhouses (PH) during 2001-2008.

\begin{tabular}{|c|c|c|c|c|c|}
\hline Year & Crop & $\begin{array}{l}\text { No. fruit } \\
\text { inspected }\end{array}$ & P. octo & C. obliquana & E. postvittana \\
\hline \multirow[t]{3}{*}{2001} & Apricot & 7,500 & 3 & & \\
\hline & Nectarine \& Peach & 10,500 & 21 & 2 & 2 \\
\hline & Cherry & $\mathrm{PH}$ & 1 & & \\
\hline \multirow[t]{3}{*}{2002} & Apricot & 25,500 & 61 & & 4 \\
\hline & Nectarine \& Peach & 15,000 & 5 & & 4 \\
\hline & Cherry & 6000 & & 1 & \\
\hline \multirow{3}{*}{2003} & Apricot & 22,500 & 4 & 2 & \\
\hline & Nectarine \& Peach & 16,500 & 4 & 1 & \\
\hline & Cherry & 1,400 & 1 & & \\
\hline \multirow[t]{3}{*}{2004} & Apricot & 25,500 & 5 & 4 & 25 \\
\hline & Nectarine \& Peach & 12,000 & 2 & 1 & 11 \\
\hline & Cherry & $\mathrm{PH}$ & & & 2 \\
\hline 2005 & Apricot & 25,500 & 1 & & \\
\hline \multirow[t]{3}{*}{2006} & Apricot & 27,200 & & & 4 \\
\hline & Nectarine \& Peach & 10,000 & & 7 & 12 \\
\hline & Cherry & $\mathrm{PH}$ & & & 1 \\
\hline \multirow[t]{3}{*}{2007} & Apricot & 28,500 & 16 & 5 & \\
\hline & Nectarine \& Peach & 15,000 & & 1 & \\
\hline & Cherry & $\mathrm{PH}$ & 1 & & \\
\hline \multirow[t]{3}{*}{2008} & Apricot & 28,500 & 10 & & 3 \\
\hline & Nectarine \& Peach & 19,000 & 1 & 1 & 5 \\
\hline & Cherry & $\mathrm{PH}$ & 2 & 1 & 3 \\
\hline \multirow[t]{4}{*}{ Total } & Apricot & 162,200 & 45 & 11 & 32 \\
\hline & Nectarine \& Peach & 98,000 & 33 & 13 & 32 \\
\hline & Cherry & $2,000+\mathrm{PH}$ & 5 & 2 & 6 \\
\hline & & & $83(46 \%)$ & $26(14 \%)$ & $70(39 \%)$ \\
\hline
\end{tabular}




\section{Packhouse inspections and insecticide use}

After harvest, all cherries were pre-cooled to $0^{\circ} \mathrm{C}$ for at least $24 \mathrm{~h}$, then hydro-cooled at $1^{\circ} \mathrm{C}$ for $12 \mathrm{~min}$, before they were graded and packed. Fruit for both export and local market were inspected for pests. In 2012/13, 648,110 cherries and 4281 apricots were inspected for insect pests.

Information was collected on the number of applications of insecticide (spinosad $40 \mathrm{ml} / 100$ litres) that were made to protect cherries from leafrollers over the 4 years from 2009/10 to $2012 / 13$. In blocks without dispensers, further applications of spinosad were made on the following dates: 15 November 2009, 15 December 2009, 5 January 2010; 15 November 2010, 23 December 2010; 26 November 2011,23 December 2011; 24 November 2012, 13 December 2012. In the blocks with dispensers, only the first spray in November was applied each year.

\section{RESULTS}

\section{Leafroller species present}

The leafroller species that occurred most frequently as larvae on stonefruit were $P$. octo and E. postvittana, with C. obliquana being less common (Table 1).

The predominant leafroller found in all stonefruit was $P$. octo, followed by E. postvittana and C. obliquana. Numbers of E. postvittana and $P$. octo from cherry were almost identical. Nine sets of pheromone traps for each of three leafroller species were managed over 16 weeks at 45 South in 2008/09, and showed that all three species were present on this orchard (Table 2). The mean numbers of male moths recorded were $10.6 \pm 6.75(\mathrm{SE})$ E. postvittana, $3.8 \pm 1.01(\mathrm{SE})$ P. octo and $2.0 \pm 0.76(\mathrm{SE})$ C. obliquana per trap over 16 weeks. There was a gradual increase in numbers of both E. postvittana and P. octo trapped in non-dispenser blocks over the 5 years. Numbers of E. postvittana were exceptionally high in 2012/13.

Catches in pheromone traps placed in areas with dispensers were very rare (Table 3 ), with $>1000$-fold fewer E. postvittana male moths caught in the presence of pheromone.

\section{Packhouse inspections and insecticide use}

In 2012/13, 648,110 cherries were inspected in the 45 South packhouse from all blocks. No leafroller larvae were found, irrespective of whether the block had had dispensers installed. Furthermore, no leafrollers were found in cherry inspections in that packhouse in the previous 4 years. In contrast, while no leafrollers were found in the 4,281 apricots inspected in 2013, one larva was found in the 11,500 apricots inspected in 2012, and three in the 12,017 apricots inspected in 2011.

Because cherries ripen relatively early in the season, few insecticides are required even on blocks without dispensers (Table 4).

One extra insecticide (spinosad) was applied to the blocks without dispensers in each year $2010 / 11$ to $2012 / 13$. Those with dispensers all received the single "highly recommended" spray in late November, described in the Summergreen (IFP) manual.

Table 2 Mean number of male moths caught per trap per day in blocks without pheromone dispensers at 45 South cherry orchards over 5 years. The total number of traps and blocks (in parentheses) are indicated.

\begin{tabular}{lccccc}
\hline $\begin{array}{l}\text { Male moths caught per trap } \\
\text { per day }\end{array}$ & $2008 / 09$ & $2009 / 10$ & $2010 / 11$ & $2011 / 12$ & $2012 / 13$ \\
\hline E. postvittana & 0.090 & 1.138 & 1.187 & 1.509 & 3.809 \\
No. traps (no. blocks) & $9(5)$ & $12(7)$ & $21(7)$ & $21(7)$ & $16(12)$ \\
P. octo & 0.032 & - & - & 0.112 & 0.249 \\
No. traps (no. blocks) & $9(5)$ & No traps & No traps & $6(2)$ & $13(12)$ \\
C. obliquana & 0.024 & - & - & - & - \\
No. traps (no. blocks) & $9(5)$ & No traps & No traps & No traps & No traps \\
\hline
\end{tabular}


Table 3 Mean number of moths of E. postvittana and P. octo trapped per day over $\sim 80$ days at 45 South in 2012/13 (standard error in parentheses).

\begin{tabular}{lcccccccc}
\hline & \multicolumn{4}{c}{ E. postvittana } & & \multicolumn{3}{c}{ P. octo } \\
\cline { 2 - 4 } & $\begin{array}{c}\text { No. } \\
\text { traps }\end{array}$ & $\begin{array}{c}\text { No. } \\
\text { trapped }\end{array}$ & No./trap/day & & $\begin{array}{c}\text { No. } \\
\text { traps }\end{array}$ & $\begin{array}{c}\text { No. } \\
\text { trapped }\end{array}$ & No./trap/day \\
\hline Dispensers (76.4 ha) & 35 & 10 & $0.0036(0.0011)$ & & 7 & 0 & 0 \\
No dispensers (65.4 ha) & 16 & 4799 & $3.809(0.5151)$ & & 13 & 257 & $0.249(0.0359)$ \\
\hline
\end{tabular}

\section{DISCUSSION}

Three species of leafroller were found attacking stonefruit in Central Otago. Two species in particular, E. postvittana and P. octo, were dominant in infested cherries. The small number of leafrollers collected and the unknown number of fruits that were inspected in the packhouses would be of concern if these results were not confirmed by the trapping programme conducted in 2008/09, which established that all three species were present at 45 South. The omission of $C$. obliquana from trapping was possible because the timing of the generations of P. octo and C. obliquana is very similar in Central Otago (McLaren \& Suckling 1993).

At 45 South, no leafrollers were found on cherries at the packhouse, in contrast to apricots, where larvae were more regularly found. This raised the possibility that fewer cherries may be naturally-infested with leafrollers than apricots, peaches or nectarines. There is a possibility that the postharvest hydrocooling treatment of cherries could contribute to the absence of leafrollers on inspected cherries (apricots are not hydrocooled), and previous research with leafroller larvae on stonefruit in water showed that this would be possible (McLaren et al. 1997). However, if the hydrocooler was causing larval mortality, there would be evidence of dead larvae found either on the fruit or in the water.
No such observations were made by the packhouse staff or inspectors. Therefore, results presented from rearing leafroller from naturallyinfested fruit from various Central Otago orchards, and inspections at 45 South, both suggest that cherries may be less susceptible to leafrollers than apricots. Apricots and cherries are both harvested at about the same time each year and have a relatively short growing season, compared with apples. Further research would be needed to investigate possible physical or biochemical differences between these two crops at the time of leafroller infestation (November/ December), which could render apricot more acceptable as a host than cherries. However, from a grower's perspective, the results confirm that cherries are a possible host for three species of leafrollers and control measures are necessary on export blocks.

The use of a single dispenser for leafroller suppression has proved to be very suitable for use in cherry, especially when applied to large blocks. Its performance was possibly improved by having all the blocks covered with nets, since this would reduce wind flow and consequently pheromone loss (Suckling et al. 1999). Leafroller suppression would appear to be holding, despite the increase in leafroller pressure in untreated blocks during the past 5 years, possibly reflecting

Table 4 Comparison of insecticide spray programmes applied to cherry blocks with and without dispensers for multiple species mating disruption of leafrollers.

\begin{tabular}{lcccccc}
\hline & & \% of area & \multicolumn{4}{c}{ Number of leafroller sprays applied (spinosad) } \\
\cline { 3 - 6 } Treatment & Area (ha) & in cherries & $2009 / 10$ & $2010 / 11$ & $2011 / 12$ & $20012 / 13$ \\
\hline Dispensers & 76.43 & 90.2 & 1 & 1 & 1 & 1 \\
No dispensers & 65.4 & 98.7 & 3 & 2 & 2 & 2 \\
\hline
\end{tabular}


the changes within the orchard as the new cherry plantings mature and are netted. Growers may need to be more vigilant in managing their plantings, especially in ground cover control, which is a possible source of infestation (Rogers et al. 2003). These results indicate that there is excellent potential for mating disruption using a single dispenser in large blocks of export cherries in Central Otago.

\section{ACKNOWLEDGEMENTS}

We are grateful to the Ministry for Business, Innovation and Employment (Sustainable IPM in Horticulture) and the Sustainable Farming Fund. We greatly appreciate the opportunity presented by 45 South Management to review their history of leafroller mating disruption outcomes in the orchard.

\section{REFERENCES}

El-Sayed AM 2013. The Pherobase: Database of Pheromones and Semiochemicals. www. pherobase.com (accessed 15/05/2013).

McLaren GF, Fraser JA, McDonald RM 1997. The feasibility of hot water disinfestation of summerfruit. Proceedings of the 50th New Zealand Plant Protection Society Conference: 425-430.

McLaren GF, Fraser J, Suckling DM 1998. Mating disruption for the control of leafrollers on apricots. New Zealand Journal of Crop and Horticultural Science 26: 259-268.

McLaren GF, Suckling DM 1993. Pheromone trapping of orchard Lepidopterous pests in Central Otago. New Zealand Journal of Crop and Horticultural Science21: 25-31.

Rogers DJ, Walker JTS, Moen IC, Weibel F, Lo PL, Cole LM 2003. Understorey influence on leafroller populations in Hawke's Bay organic apple orchards. New Zealand Plant Protection 56: 168-173.
Singh P 1983. A general purpose laboratory diet mixture for rearing insects. Insect Science Application 4: 357-362.

Suckling D, Rogers D, Shaw P 1990. Disruption of light-brown apple moth Epiphyas postvittana (Walker)(Lepidoptera, Tortricidae) trapping in Nelson, New-Zealand. Australian Journal of Zoology 38: 363-373.

Suckling DM, Green SR, Gibb AR, Karg G 1999. Predicting atmospheric concentration of pheromone in treated apple orchards. Journal of Chemical Ecology 25: 117-139.

Suckling DM, Walker JTS, Clare GK, Boyd Wilson KSH, Hall C, El-Sayed AM, Stevens PS 2012a. Development and commercialisation of pheromone products in New Zealand. New Zealand Plant Protection 65: 267-273.

Suckling DM, McLaren GF, Manning LM, Mitchell VJ, Attfield B, Colhoun K El-Sayed AM 2012b. Development of single dispensers for suppression of Epiphyas postvittana, Planotortrix octo and Ctenopseustis obliquana in New Zealand stonefruit orchards. Pest Management Science 68: 928-934.

Walker J, Rogers D, Lo P, Suckling D, El-Sayed AM, Fraser T, Horner R 2011. Use of mating disruption for control of New Zealand leafrollers in apple orchards. New Zealand Plant Protection 64: 215-221.

Witzgall P, Kirsch P, Cork A 2010. Sex pheromones and their impact on pest management. Journal of Chemical Ecology 36: 80-100. 